\title{
Human milk: maternal dietary lipids and infant development
}

\author{
Sheila M. Innis \\ Nutrition Research Program, Child and Family Research Institute, University of British Columbia, 950 West 28th Avenue, \\ Vancouver, BC V5Z 4H4, Canada
}

\begin{abstract}
Human milk provides all the dietary essential fatty acids, linoleic acid (LA; 18:2n-6) and $\alpha$-linolenic acid (18:3n-3), as well as their longer-chain more-unsaturated metabolites, including arachidonic acid (20:4n-6) and DHA (22:6n-3) to support the growth and development of the breast-fed infant. Human milk levels of LA have increased in Westernized nations from mean levels ( $\mathrm{g} / 100 \mathrm{~g}$ total fatty acids) of 6 to $12-16$ over the last century, paralleling the increase in dietary intake of LA-rich vegetable oils. DHA levels $(\mathrm{g} / 100 \mathrm{~g}$ total milk fatty acids) vary from $<0 \cdot 1$ to $>1 \%$ and are lowest in countries in which the intake of DHA from fish and other animal tissue lipids is low. The role of DHA in infant nutrition is of particular importance because DHA is accumulated specifically in the membrane lipids of the brain and retina, where it is important to visual and neural function. An important question is the extent to which many human diets that contain low amounts of $n-3$ fatty acids may compromise human development. The present paper reviews current knowledge on maternal diet and human milk fatty acids, the implications of maternal diet as the only source of essential fatty acids for infant development both before and after birth, and recent studies addressing the maternal intakes and milk DHA levels associated with risk of low infant neural system maturation.
\end{abstract}

Human milk: Essential fatty acids: $\boldsymbol{n - 3}$ Fatty acids: Infant development

Human milk provides a complex array of lipids that contribute energy, as well as the essential $n-6$ and $n$-3 PUFA to support the growth and development of the breast-fed infant. Although the maternal diet has little effect on the amount of fat or the distribution of lipid classes secreted in milk, the levels of unsaturated fatty acids are highly dependent on the types of fatty acids in the maternal diet. Over 200 fatty acids of different chain length and unsaturation have been identified in human milk, and they include the $n-6$ and $n-3$ fatty acids linoleic acid (LA; 18:2n-6) and $\alpha$-linolenic acid (ALA; 18:3n-3) and their longer-chain metabolites arachidonic acid (ARA; 20:4n-6) and EPA (20:5n-3) and DHA (22:6n-3) respectively (Jensen, 1999; Innis, 2004). The levels of $n-6$ and $n-3$ fatty acids, particularly LA, ALA and DHA, in human milk vary widely within and among different populations, and they are readily changed by the maternal dietary intake of the respective fatty acid (Innis, 1992, 2004). This variability in human milk fatty acids results in considerable differences in the intake and blood levels of $n-6$ and $n-3$ fatty acids among breast-fed infants. The role of DHA in the infant diet has received particular attention because DHA is selectively enriched in a few particular membrane lipids, which include the glycerophospholipids of the visual elements of the retina and brain grey matter. Importantly, DHA plays critical roles in the visual and neural systems, including such roles as protection from oxidative damage, neurogenesis, neurotransmitter metabolism, membrane protein functions, transmission of the visual signal and regulation of gene expression (Innis, 2007). The present paper reviews recent understanding of PUFA in human milk, with a focus on maternal dietary lipids and DHA, and the implications for infant development.

\section{Milk fat synthesis and composition}

Milk fat consists predominantly of PUFA, which represent about $98 \mathrm{~g} / 100 \mathrm{~g}$ milk total fat and are synthesized from glycerol and NEFA in the alveolar cells of the mammary gland (Jensen, 1999; Neville, 2001). Fatty acids of $\mathrm{C}_{\geq 16}$ are taken up from plasma chylomicrons and VLDL-PUFA through the action of the mammary lipoprotein lipase. As such, the fatty acids in human milk may originate either from the recent dietary fatty acid intake, from fatty acids released from maternal adipose tissue or from de novo 
synthesis or further metabolism of dietary fatty acids in the maternal liver. Fatty acid synthesis in the mammary gland proceeds via the fatty acid synthetase enzyme complex, commencing with acetyl-CoA, followed by sequential addition of $\mathrm{C}_{2}$ units as malonyl-CoA, as in other cells. In tissues other than the mammary gland long-chain acyl thioesterase is part of the fatty acid synthetase complex and cleaves the fatty acyl chain at $\mathrm{C}_{16}$ to give rise to the SFA palmitic acid (16:0). In the mammary gland the cytosolic medium-chain acyl thioesterase, thioesterase 11 , cleaves the fatty acyl chain at $\mathrm{C}_{14}$ to generate myristic acid (14:0), which explains the presence of medium-chain fatty acids in human milk and their increase during highcarbohydrate diets (Hachey et al. 1989). Conversion of acetyl-CoA to malonyl-CoA catalysed by acetyl-CoA carboxylase is the rate-limiting step in fatty acid synthesis and is regulated by insulin in a similar manner to that in other tissues. Several important differences in mammary gland fatty acid synthesis and in the effect of dietary lipids on milk fatty acids occur between ruminants and nonruminants. In ruminants the primary sources of $\mathrm{C}$ for mammary-gland fatty acid synthesis are acetate and $\beta$-hydroxybutyrate, and as a result of metabolism by the rumen bacteria dietary fatty acids have little influence on the composition of cow's milk fatty acids (Jensen et al. 1990). Cow's milk typically contains <2 g LA and ALA/ $100 \mathrm{~g}$ total fatty acids and has negligible amounts of EPA and DHA. In man glucose-derived acetyl-CoA is the major source of $\mathrm{C}_{2}$ units for fatty acid synthesis, and the maternal dietary intake of PUFA has a marked effect on the amounts of $n-6$ and $n-3$ fatty acids secreted in milk (Innis, 1992, 2004; Jensen, 1999).

The long-chain SFA, cis-MUFA, trans-fatty acids and $n-6$ and $n-3$ PUFA are taken up by the mammary gland and then acylated into PUFA for secretion in milk. Mammary gland-specific acyl transferases preferentially esterify 16:0 and $18: 0$ at the centre $s n-2$ position of the human-milk PUFA, rather than at the $s n-1$ or $s n-3$ positions, as in other tissues (Jensen et al. 1990; Innis, 2004). The products of hydrolysis of human-milk PUFA hydrolysis by gastric and pancreatic lipases are NEFA released from the PUFA $s n-1$ and $s n-3$ positions and $s n-2$ monoacylglycerols enriched in 16:0 and 18:0 (Innis et al. 1994). This unusual structure of human-milk PUFA is believed to be important because non-esterified 16:0 and 18:0 have melting points (about $63^{\circ} \mathrm{C}$ and $69^{\circ} \mathrm{C}$ respectively) that are considerably above body temperatures and readily form insoluble soaps with $\mathrm{Ca}$ and other divalent cations at the $\mathrm{pH}$ of the intestine, resulting in faecal loss of both fat and important minerals (Kennedy et al. 1999). Whether in breast-fed infants the distribution of fatty acids in the plasma chylomicron PUFA with 16:0 and 18:0 in the centre position also influences tissue $n-6$ and $n-3$ fatty acid delivery is not known. After absorption $s n-2$ monoacylglycerols are re-esterfied mainly via the 2-monoacylglycerol pathway, thus preserving the unusual position of fatty acids in human milk fat (Innis et al. 1994).

LA and ALA cannot be formed by mammalian cells, and as a result all the $n-6$ and $n-3$ fatty acids secreted in milk must be derived from the maternal diet, either directly or after storage or further metabolism in maternal tissues.
LA and ALA are present in the diet in greatest amounts in unsaturated plant, seed and nut oils, although different oils vary considerably in their LA and ALA content (Innis, 2004). Once obtained from the diet LA and ALA can be further metabolized by $\triangle 6$-desaturation, elongation and $\Delta 5$-desaturation to form ARA and EPA respectively. The generally-accepted pathway for further metabolism of EPA to DHA is that proposed by Sprecher (1999). It involves two successive elongations of EPA to form 24:5n-3, then desaturation at position 6 to yield 24:6n-3, which is then translocated to the peroxisomes where a single cycle of $\beta$-oxidation generates 22:6n-3 (Innis, 2003). Further metabolism of $n-6$ fatty acids to form docosapentaenoic acid $(22: 5 n-6)$ is believed to occur through an analogous pathway. A characteristic feature of animals fed an $n-3$ fatty acid-deficient $n-6$ fatty acid-sufficient diet is a decrease in tissue levels of DHA and an increase in $n-6$ docosapentaenoic acid (Innis, 1991, 2003). Essential fatty acid deficiency involving an inadequate intake of both $n-6$ and $n-3$ fatty acids, on the other hand, results in a decrease in ARA and DHA and increased desaturation and elongation of the $n-9$ fatty acid oleic acid (18:1n-9) to give increased levels of 20:3n-9 and 22:3n-9 (Innis, 1991).

As the synthesis of ARA, EPA, DHA and their intermediates is limited to animal cells, they are found in the diet only as part of animal tissue lipids (Innis, 2003). While the richest dietary source of EPA and DHA is fish, most dietary ARA is derived from poultry and other meats (Kris-Etherton et al. 2000; RW Freisen and SM Innis, unpublished results). ARA, EPA and DHA secreted into milk may originate either from the maternal diet or as a result of synthesis from their LA and ALA precursors respectively in the maternal tissues. In vitro the $\Delta 6$-desaturase that catalyses the first step in fatty acid desaturation shows substrate preference in the order ALA $>$ LA $>$ oleic acid (Innis, 1991). However, in vivo a considerable proportion of ALA undergoes $\beta$-oxidation for energy, rather than undergoing desaturation and elongation, and as a result only small amounts of ALA are converted to DHA. The conversion of ALA to EPA and DHA in man, when estimated on the basis of the appearance of products of stable-isotope tracers of ALA in plasma, is very low, with $<1 \%$ of the ALA converted to EPA and $<0.1 \%$ converted to DHA (Williams \& Burdge, 2006). $\Delta 6$ - and $\Delta 5$-desaturases are expressed in rat mammary gland and enzyme expression is reduced by a maternal diet high in LA (Rodriguez-Cruz et al. 2006). Currently, it is not known whether mammary gland LA or ALA desaturation contributes to the levels of longer-chain $n-6$ and $n-3$ fatty acids in human milk, or if such pathways, if present, are influenced by the maternal dietary LA intake. At present, there is no indication that mammary gland fatty acid desaturases contribute physiologically-relevant amounts of DHA to human milk.

\section{Maternal dietary lipids and their effect on the composition of milk fat}

The presence in human milk of a large number of fatty acids of different chain length and unsaturation, including 
many geometric and positional isomers, and the wide variability in milk fatty acid compositions among women have been known for many years. However, only recently has interest been directed towards the possibility that maternal lipid nutrition may adversely effect, as well as promote, the growth and development of the breastfed infant. Observational and intervention studies have shown that levels of trans-fatty acids, oleic acid, LA, ALA and DHA in human milk show considerable variability, explained largely by the amount of the respective fatty acid in the maternal diet. For example, levels of transfatty acids derived from industrial hydrogenation of cisunsaturated vegetable oils are higher in human milk in North America than in Europe, with levels as high as $18 \mathrm{~g}$ trans-fatty acids $/ 100 \mathrm{~g}$ total fatty acids in the milk fat of some women (Innis, 2006). High amounts of trans-fatty acids in human milk have raised concerns because of the possible adverse effects on essential fatty acid and lipid metabolism, as well as incorporation of unusual fatty acid isomers into the infant's tissues (Innis, 2006). The levels of trans-fatty acids in human milk in Canada have now decreased with the introduction of food labelling and regulations to restrict the amounts of trans-fatty acids in retail foods (Friesen \& Innis, 2006).

The effects of maternal dietary fat composition on the $n-6$ and $n-3$ fatty acid composition of human milk fatty acids are clearly shown by: a consideration of the changes in human-milk fatty acids over the last 50 years; a comparison of human milk fatty acids among women following vegan or mixed diets of different fat composition; the results of controlled interventions to alter maternal dietary fat intake. Early studies by Insull et al. (1959) have shown an LA content ( $\mathrm{g} / 100 \mathrm{~g}$ total fatty acids) of $7 \cdot 7$ in milk from women following their usual diet, which increases 4-fold to 41.4 when the diet is changed to $40 \%$ energy from maize oil (usual LA content of about 52) and to $10 \cdot 4$ when the diet has $40 \%$ energy from lard (LA content of about 10). Later studies in the 1960s have noted mean concentrations of $9 \cdot 5 \mathrm{~g} \mathrm{LA} / 100 \mathrm{~g}$ total fatty acids in human milk (Tomarelli et al. 1968). The mean levels of LA in human milk among women in the USA, Canada and Europe in most studies conducted from 1980 onwards are $12-16 \mathrm{~g} / 100 \mathrm{~g}$ total fatty acids (Innis, 1992; Jensen, 1999). However, the amount of LA in human milk varies widely among individual women, from about $6 \mathrm{~g} / 100 \mathrm{~g}$ total fatty acids to $>30 \mathrm{~g} / 100 \mathrm{~g}$ total fatty acids in the milk fat of vegetarians (Innis \& King, 1999; Jensen, 1999; Sanders \& Reddy, 1992). In the population studied in Vancouver, Canada, LA in human milk (g/100 g total fatty acids) ranges from 6 to 22 (Innis \& King, 1999). Assuming an average of $3.7 \mathrm{~g}$ fat and $315 \mathrm{~kJ}(75 \mathrm{kcal}) / 100 \mathrm{ml}$ milk and an intake of $780 \mathrm{ml} / \mathrm{d}$ by the infant, then the average and range of LA intake (g/d) among breast-fed infants are $3 \cdot 46$ and $1.73-6 \cdot 20$ respectively, equivalent to $5 \cdot 3$ and $2 \cdot 7-9 \cdot 5 \%$ total energy intake respectively. There is a high positive correlation between the LA content of human milk and the LA levels in the plasma PUFA and phospholipids in the recipient breast-fed infant (Innis \& King, 1999). Several conclusions can be drawn. First, all human milk meets and exceeds the dietary requirements for $n-6$ fatty acids, which is met by an intake of only $1-2 \%$ energy from LA (Innis,
1991). Second, the intake of LA by the breast-fed infant is similar to that of adults in the same population. The high level of LA in Western diets has led to concern, particularly in relation to the concurrent low intake of $n-3$ fatty acids and the increasing prevalence of many inflammatory and immune disorders (Simopoulos, 1999; Calder, 2006). Consequently, this area of infant nutrition is now becoming the subject of increasing interest, which should be extended to human milk lipids and the impact on the breast-fed infant (Calder et al. 2006; Innis et al. 2006).

Similar to LA, the levels of DHA in human milk also vary widely within and among populations (Innis, 1992, 2004), which again results in differences in the plasma and cell membrane levels of DHA among breast-fed infants (Gibson et al. 1997; Innis \& King, 1999; Jensen et al. 2000; Innis et al. 2001). Milk fat from women following vegan diets, which lack DHA, contains < $<11 \mathrm{~g}$ DHA/100 g total fatty acids (Sanders \& Reddy, 1992), whereas much higher amounts, often $>1 \mathrm{~g}$ DHA $/ 100 \mathrm{~g}$ total fatty acids, are found in the milk of women consuming diets high in fish and other marine animals (Innis, 1992, 2004). The mean levels of DHA (g/100 g total fatty acids) in milk from women in Canada, the USA, Europe and Australia is 0·2-0·3 (Jensen, 1999; Innis, 1992, 2004), while population averages range from 0.07 in milk fat from women in some areas of Africa to 1.0 in milk fat of women in Japan (Innis, 2004; Yukas et al. 2006). In the study centre in Vancouver lactating women who exclusively breast-feed their healthy term infants and consume about $81 \mathrm{mg} \mathrm{DHA} / \mathrm{d}$ have $0 \cdot 17 \mathrm{~g}$ DHA/ $100 \mathrm{~g}$ total fatty acids in their milk fat at $30 \mathrm{~d}$ postnatally, while women who consume $131 \mathrm{mg}$ DHA/d have $0 \cdot 32 \mathrm{~g} \mathrm{DHA} / 100 \mathrm{~g}$ total fatty acids (Fig. 1). Studies in Norway, on the other hand, have shown mean levels of $0.5 \mathrm{~g} \mathrm{DHA} / 100 \mathrm{~g}$ total fatty acids in milk fat at 1 month post partum among women with a dietary intake of $200 \mathrm{mg}$ DHA/d (Helland et al. 2001).

Similarly to LA, the consideration of mean levels of DHA in milk among groups of women hides the wide variability among individuals, which in the Vancouver study population extends from $<0 \cdot 1 \mathrm{~g}$ DHA/ $100 \mathrm{~g}$ total fatty acids to $1.0 \mathrm{~g}$ DHA $/ 100 \mathrm{~g}$ total fatty acids in the milk fat of women who are not taking DHA supplements (Innis \& King, 1999; Friesen \& Innis, 2006). This range in mean values is similar across different countries (Innis, 1992, 2004; Jensen, 1999; Yukas et al. 2006). Assuming an average of $3.7 \mathrm{~g}$ fat and $315 \mathrm{~kJ}(75 \mathrm{kcal}) / 100 \mathrm{ml}$ milk and an intake of $780 \mathrm{ml} / \mathrm{d}$ by the infant, then the average intake of DHA among breast-fed infants consuming milk with $0 \cdot 2 \mathrm{~g} \mathrm{DHA} / 100 \mathrm{~g}$ total fatty acids is $0.056 \mathrm{~g} / \mathrm{d}$, representing $0.086 \%$ total energy. A range of $0 \cdot 1-1 \cdot 0 \mathrm{~g} \mathrm{DHA} / 100 \mathrm{~g}$ total fatty acids in human milk fat is equivalent to a potential DHA intake ranging from $0.028 \mathrm{~g} / \mathrm{d}$ to $0.280 \mathrm{~g} / \mathrm{d}$, or from $0.04 \%$ total energy intake to $0.4 \%$ total energy intake from DHA among breast-fed infants. Although theoretical, these estimations illustrate a very wide variation in $n-3$ fatty acid intakes, as well as $n-6$ fatty acid intakes, among breast-fed infants.

An increase in DHA intake among lactating women through supplementation with fish, fish oils, single-cell PUFA, DHA-enriched eggs or other sources of DHA increases the secretion of DHA in milk, and increases the 


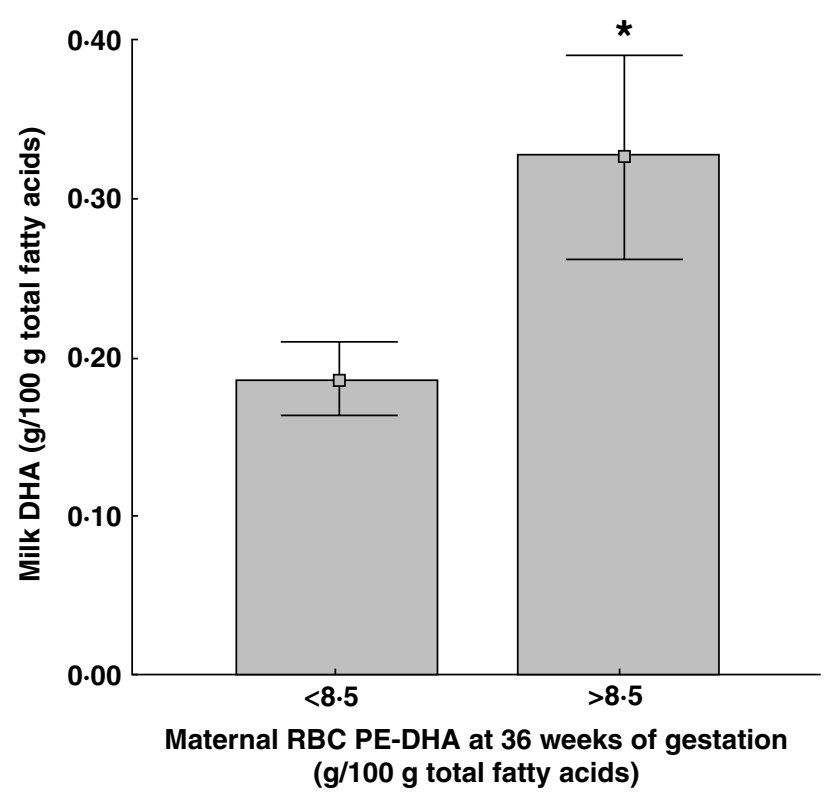

Fig. 1. Concentration of DHA in milk fat at $30 \mathrm{~d}$ postnatally among women with an erythrocyte phosphatidylethanolamine (RBC PE)DHA of $<8.5$ or $>8.51 \mathrm{~g} / 100 \mathrm{~g}$ total fatty acids at 36 weeks of gestation ( $n 17$ and $n 22$ respectively) who exclusively breast-fed their term-gestation infants. Values are means with their standard errors represented by vertical bars. Mean value was significantly different from that for the higher concentration of maternal RBC PE-DHA: ${ }^{*} P<0.05$.

plasma and erythrocyte (RBC) levels of DHA in the recipient breast-fed infant (Henderson et al. 1992; Gibson et al. 1997; Fidler et al. 2000; Jensen et al. 2000). Increased intakes of ALA, however, have been shown in an intervention study using supplements of ALA and supplements of DHA to have little or no effect in increasing the secretion of DHA in human milk (see Innis, 2004). In summary, observational and intervention studies concur that the most important factor determining the secretion of DHA in human milk is the mother's intake of DHA. Since maternal fatty acid nutrition impacts on the quality of human milk fatty acids, consideration is needed as to what lipid nutrition meets the needs of the mother herself and that required to support optimal growth and development of her infant.

\section{PUFA in human milk and the breast-fed infant}

Human milk provides the only source of $n-6$ and $n-3$ fatty acids to support the growth and development of the breastfed infant during breast-feeding and for much of early infancy, when foods such as Fe-fortified infant cereals, vegetables, fruits and dairy products, all of which are low in $n-6$ and $n-3$ fatty acids unless fortified, are added to the infant diet.

Particularly high concentrations of DHA are present in phosphatidylserine and the ethanolamine phosphoacylglycerols (ethanolamine plasmalogen and phosphatidylethanolamine $(\mathrm{PE})$ ) of brain grey matter and the outer segments of rod and cone photoreceptors in the retina
(Innis, 2003). DHA comprises $\leq 80 \%$ of the PUFA in the retina outer segment disks, and phospholipids are present in which both fatty acids are DHA. In vitro studies have provided evidence that DHA plays a role in photoreceptor signal transduction by influencing the ability of photons to transform rhodopsin to the activated meta-rhodopsin 11 state and the efficiency of G-protein-coupled receptor signalling (Niu et al. 2004). More recently, it has been shown (Soubias et al. 2006) that there are specific binding sites for DHA in the rhodopsin molecules. In the brain DHA is enriched in synaptic terminal membranes and has diverse roles in brain growth and function and in protecting against oxidative stress (Innis, 2007). Although much remains to be understood, recent experimental studies have shown (Bazan, 2006; Innis, 2007) that reduced levels of DHA in the brain impair neurogenesis and neurite outgrowth and alter the metabolism of several neurotransmitters, including dopamine, serotonin and acetylcholine. DHA is also a ligand for nuclear hormone transcription factors, targets for which include genes involved in synaptic plasticity, endocytosis, signal transduction and synaptic vesicle recycling, and the precursor to resolvins and neuroprotectins that protect against oxidative damage.

Thus, DHA is important in the central nervous system, is present in human milk and early deficiencies in key nutrients have the potential to result in long-term effects on cognitive and behavioural functions. These factors have stimulated intense interest in the role of DHA in infant nutrition, particularly in relation to the fatty acid composition of infant formulas (Lauritzen et al. 2001; Heird \& Lapillonne, 2005; Fewtrell, 2006; Uauy \& Dangour, 2006). Growth of membrane structures, involving cell division, myelination and such processes as neurite extension and dendritic arborization, requires the synthesis of large amounts of new membrane material, which results in a high demand for DHA. The rate of brain growth is at peak velocity during the last 3 months of gestation and the first few months after birth (Innis, 1991), leading to a general concept that DHA requirements in the human infant may be particularly high during the later stage of gestation and in early infancy.

It is now well known that the inclusion of DHA in infant formulas increases DHA in a dose-dependent manner in the blood lipids of infants fed formula (Makrides et al. 1995; Carlson et al. 1996; Innis et al. 1996; Birch et al. 1998). In addition, some studies (Birch et al. 1998, 2000; Hoffman et al. 2003) have reported that the addition of DHA to infant formulas increases visual and neural system maturation in term-gestation infants who are fed formula from birth or after initial breast-feeding. Similarly, although less well appreciated, the circulating blood levels of DHA in breast-fed infants depend on the concentration of DHA in the mother's milk, which in turn depends on the amount of DHA in the mother's diet (Gibson et al. 1997; Innis \& King, 1999; Fidler et al. 2000; Jensen et al. 2000; Innis et al. 2001). Early studies by Sanders \& Reddy (1992) have shown levels of 1.9 (SE 0.32) g DHA/100 g RBC total fatty acids in breast-fed infants whose mothers followed a vegan diet (and thus devoid of DHA) compared with $6 \cdot 2$ (SE 0.41) g DHA/100 g RBC total fatty acids in breast-fed infants whose mothers followed mixed diets. In 


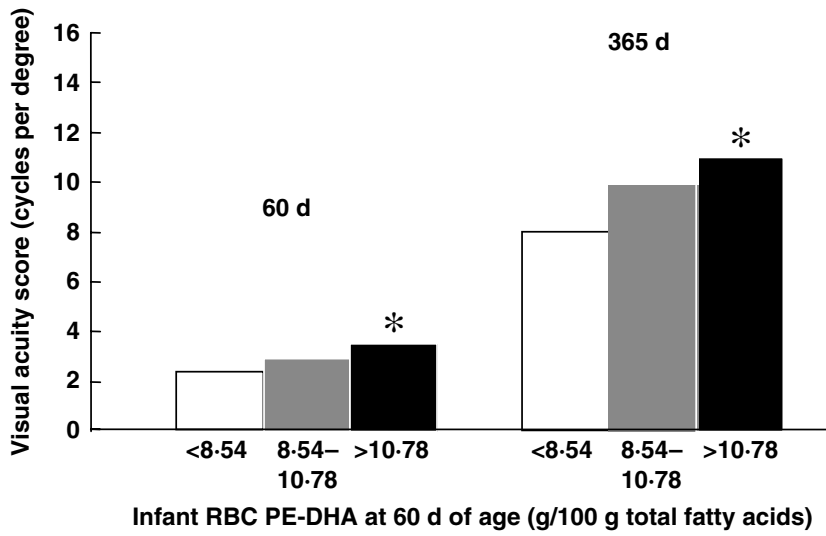

Fig. 2. Visual acuity at 60 and $365 \mathrm{~d}$ of age among term-gestation infants grouped by tertile of erythrocyte phosphatidylethanolamine (RBC PE)-DHA status at $60 \mathrm{~d}$ of age, at which time all infants were breast-fed. The mean DHA in the mothers' milk of infants in the lower, middle and upper tertile was $0.17,0.22$ and $0.31 \mathrm{~g} / 100 \mathrm{~g}$ total milk fatty acids respectively. Visual acuity at 60 and $365 \mathrm{~d}$ of age was significantly higher among infants in the highest tertile compared with lowest tertile: ${ }^{*} P<0 \cdot 05$. (Adapted from Innis et al. 2001.)

the same study the RBC fatty acids of infants fed formula with no DHA were found to contain 3.7 (SE 0.21) g DHA/ $100 \mathrm{~g}$. As in adults, increasing the dietary intake of ALA has no measurable effect in increasing blood levels of DHA in young infants (Ponder et al. 1992). These findings suggest that DHA intake, either from the mother's breast milk or infant formula, is the most important determinant of the infant's blood levels of DHA. Research by the author's group in Canada has focused on the variability in maternal dietary DHA intake, and the implications for infant development of low maternal DHA status during both gestation and lactation.

A prospective approach has first addressed whether the variability in human milk DHA is likely to be related to visual and neural development among breast-fed infants (Innis et al. 2001; Innis, 2003). Healthy term-gestation infants ( $n$ 88) were assessed using measures of visual acuity, language, mental and motor skill development from birth to 18 months of age, and the Standford-Binet intelligence test was undertaken at 5 years of age. Milk samples and infant blood samples were collected at $60 \mathrm{~d}$ after birth, at which time all the infants were exclusively breast-fed. The results show that infants in the lowest tertile of RBC PE-DHA at $60 \mathrm{~d}$ of age have significantly lower visual acuity at 60 and $365 \mathrm{~d}$ of age than infants in the highest tertile of RBC PE-DHA (Innis et al. 2001; Fig. 2). The analysis of the mother's milk fat indicates that infants in lowest, middle and highest tertile of DHA status were fed milk containing mean levels of DHA of $0 \cdot 17,0.20$ and $0 \cdot 31 \mathrm{~g} / 100 \mathrm{~g}$ total fatty acids respectively. Multivariate analysis controlling for environmental, maternal and infant variables that are known to influence infant development shows that infant DHA status at $60 \mathrm{~d}$ of age is related to language development at 9 and 18 months of age, although there are no significant relationships with scores for the
Bayley Scales of Mental or Motor Skill Development at 18 months of age or with tests of novelty preference at 9 months of age (Innis et al. 2001; Innis, 2003). In agreement with this work, studies in other countries (Jorgensen et al. 2001; Lauritzen et al. 2004) have also shown a positive relationship between human milk levels of DHA and visual function maturation in breast-fed infants. Some studies (Helland et al. 2003; Jensen et al. 2005) have reported an association between infant DHA status at birth or during breast-feeding and scores for tests of cognitive function when measured later in early childhood. In a follow-up of fifty-five infants from the Vancouver studies (Innis et al. 2001; Innis, 2003), however, correction could not be made for the concurrent child diet at 5 years of age, and it was found that mothers with low milk levels of DHA whose children had a low DHA during breast-feeding also fed their child diets low in DHA. It is recognized that, although consistent with an important role of DHA in retinal and neural function, other dietary or lifestyle variables could explain the statistical associations between DHA and infant development (Innis et al. 2001; Innis, 2003). Also evident is the strong probability that women with low intakes of DHA during lactation also have low intakes of DHA in gestation, which could have long-term effects secondary to the role of DHA in neurogenesis (Innis, 2007).

The current studies in Vancouver are investigating whether women with low levels of DHA in their milk also have a low DHA status in gestation. Using dietary intervention with DHA, these studies are also investigating whether $n-3$ fatty acid deficiency occurs among pregnant and lactating women and whether it poses a risk of reduced visual and neural system maturation among infants in the study population. Women are asked to take a supplement of $400 \mathrm{mg} \mathrm{DHA} / \mathrm{d}$ from single-cell PUFA or a maizesoybean oil placebo from 16 weeks of gestation until delivery. Maternal dietary intake and blood lipid DHA are determined at 16 and 36 weeks of gestation, milk fatty acids are analysed at $30 \mathrm{~d}$ after delivery and infant visual, mental and motor skill development are assessed to 18 months of age. Several concepts not previously considered in studies on DHA and infant development, but which are important in nutritional studies in individuals not known to have deficiency, are included. First, because the relationship between the intake of an essential dietary factor and functions dependent on that factor is not linear but plateaus at intakes equal to and above need, only the individuals who are deficient can benefit from intervention. However, since blood levels of DHA continue to increase with increasing DHA intake, a linear relationship between DHA intake or blood levels of DHA and measures of functions dependent on DHA can occur only when all or almost all individuals in the group are deficient. Careful studies in animals have shown that dietary $n-3$ fatty acid deficiency results in reduced retinal and visual acuity (Innis, 1991), and clinical studies concur that infant visual acuity at $60 \mathrm{~d}$ of age is the most robust reproducible measure of inadequate DHA (SanGiovanni et al. 2000). Different from drug studies, in the Vancouver dietary study the placebo group is not a non-exposure group, and overlap will occur between individuals in the placebo 
group with a high habitual DHA intake and deficient individuals in the DHA intervention group with a low DHA intake. Analysis of the RBC-membrane PE is used as a measure of DHA status because it avoids problems in the analysis of fatty acids in plasma total lipids or phospholipids that results from short-term dietary effects and heterogeneity in plasma lipoproteins (VLDL, LDL and HDL) in which lipids (cholesteryl esters, TAG, phospholipids) are carried. Maternal blood is collected at 36 weeks of gestation to avoid possible variables associated with labour and delivery.

Whether women with low levels of DHA in their milk also have a low DHA status in gestation is demonstrated by the milk fat levels of $0 \cdot 17$ and $0 \cdot 32 \mathrm{~g}$ DHA/ $100 \mathrm{~g}$ total fatty acids at $30 \mathrm{~d}$ postnatally for women who had an RBC PE-DHA of $<8.5(n$ 17) and $>8.5(n 22) \mathrm{g} / 100 \mathrm{~g}$ total fatty acids at 36 weeks of gestation respectively $(P<0.05$; Fig. 1). Dietary analyses show that the intakes of DHA are also different (81 (SE 2) and 131 (SE 2) $\mathrm{mg} / \mathrm{d}$ respectively for the two groups; $P<0 \cdot 05)$. These prospective studies establish that women with low DHA levels in their milk also have low blood levels of DHA and low DHA intakes in gestation. The presence of $n-3$ fatty acid deficiency is revealed by the effect of DHA intervention on the maternal blood lipid fatty acids and infant visual acuity scores. Women in the placebo group who took the maize-soybean oil placebo were found to have RBC PE-DHA levels at 16 and 36 weeks of gestation of $9 \cdot 0$ (SE 0.31 ) and $8 \cdot 6$ (SE $0 \cdot 31) \mathrm{g} / 100 \mathrm{~g}$ total fatty acids, respectively. However, women assigned to $400 \mathrm{mg}$ DHA/d were found to have a $42 \%$ higher RBC PE-DHA level (12.3 (SE 0.31) g/100 g total fatty acids; $P<0 \cdot 001$ ) at 36 weeks. An increase in $\mathrm{C}_{22}$ $n-6$ fatty acids, particularly docosapentaenoic acid, occurs in animals fed an $n$-3 fatty acid-deficient diet (Innis, 1991). Women in the placebo group were found to show a significant increase in docosapentaenoic acid $(\mathrm{g} / 100 \mathrm{~g}$ total fatty acids) between 16 and 36 weeks of gestation (from 0.82 (se 0.05 ) to 1.08 (se 0.05$) ; n 50 ; P<0.01$ ), as compared with the DHA intervention group (0.95 (SE 0.06) and 0.73 (SE 0.03 ) respectively ( $n 49) ; P<0.005$ ). The increase in $n-6$ docosapentaenoic acid with no change in DHA in the placebo group is consistent with increased fatty acid desaturation in pregnancy (Williams \& Burdge, 2006), but proceeding with $n-6$ fatty acids because of inadequate $n-3$ fatty acid nutrition. In the absence of $n-3$ fatty acid deficiency visual acuity scores should not differ among 60-dold infants grouped into tertiles based on their mother's DHA status during gestation. However, as shown in Fig. 3, mean visual acuity scores (expressed in cycles per degree and SD expressed in octaves, where one cycle per degree is equivalent to $0 \cdot 301$ octaves) were found to be significantly lower among infants in the lowest tertile of maternal DHA status compared with those in the highest tertile $(2 \cdot 21$ (sD $0 \cdot 51 ; n 22$ comprising $n 21$ for placebo and $n 1$ for DHA intervention) v. 2.44 (SD 0.48; $n 17$ comprising $n 2$ for placebo and $n 15$ for DHA intervention); $P<0 \cdot 05$ ). The mean visual acuity scores were 2.33 cycles per degree (SD 0.59 octaves; $n 50$ comprising $n 27$ for placebo and $n 23$ for DHA intervention) for infants in the middle tertile of maternal DHA status. Multivariate analyses, including maternal DHA status, supplement group, infant gender,

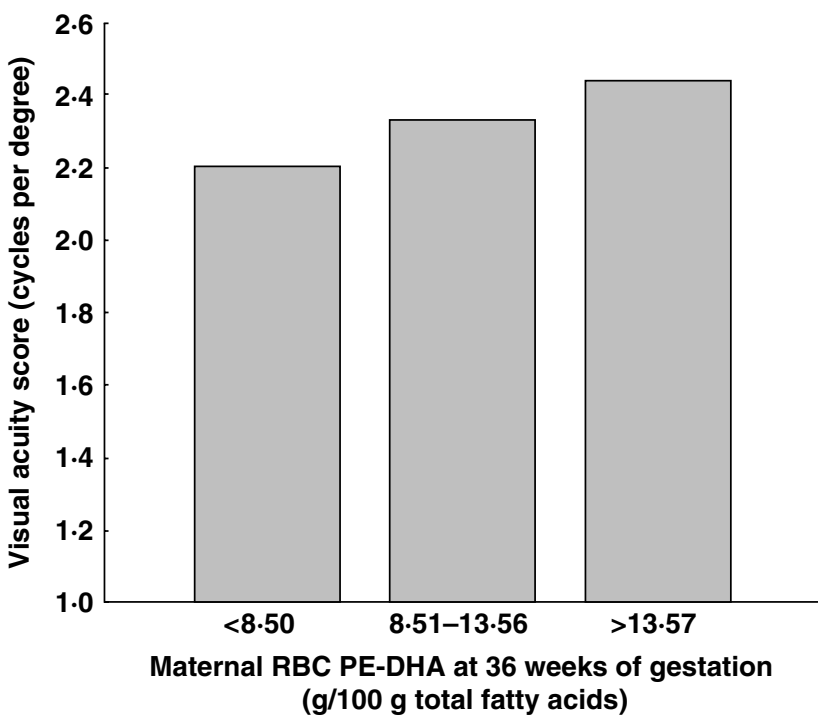

Fig. 3. Visual acuity scores at $60 \mathrm{~d}$ of age among infants grouped according to their mother's DHA status at 36 weeks of gestation. The no. of infants whose mothers were assigned to placebo or $400 \mathrm{mg} \mathrm{DHA} / \mathrm{d}$ from 16 weeks of gestation until delivery were respectively (according to tertile of erythrocyte phosphatidylethanolamine (RBC PE)-DHA; $\mathrm{g} / 100 \mathrm{~g}$ total fatty acids): $<8.50,21,1$; $8 \cdot 51-13 \cdot 56,27,33 ;>13 \cdot 57,2,15$. Visual acuity scores were significantly lower among infants in the lowest tertile compared with the highest tertile $(P<0.05)$. Using multivariate regression DHA supplementation was associated with a 2-fold decrease in the risk of a visual acuity score of $<2.32$ cycles/degree (the mean score of the study population ( $n$ 99); OR 2:1).

birth weight, length, gestational age at birth, breastfeeding, breast-feeding duration and maternal ethnicity, which together account for $86 \%$ of the variability in infant visual acuity at $60 \mathrm{~d}$ of age, show that infants in the placebo group have a 2-fold greater risk (OR 2:1) of having a visual acuity score of $<2.32$ cycles/degree (the mean score of the study population; $n$ 99). The mean visual acuity scores of infants in the DHA intervention and placebo group were not significantly different (cycles per degree; 2.40 (SD 0.53 octaves) and 2.24 (SD 0.53 octaves) respectively; $P>0.05$ ), which is explained by the large overlap of sufficient and deficient individuals in the placebo and DHA group respectively. As maternal DHA supplementation decreases the risk of low infant visual acuity, it is likely that the higher proportion of infants with low visual acuity scores in the placebo group is explained by inadequate $n-3$ fatty acid nutrition among pregnant and lactating women in the study population. However, the studies do not separate the effects of low maternal DHA status in gestation and lactation. While it is of biological interest to separate the effects of maternal fatty acid nutrition on infant development before and after birth, and this approach does have relevance to the design of human milk substitutes, in practice women with low intakes of DHA in lactation also have low intakes of DHA in gestation. The results of the observational and intervention studies could suggest that increased risk of inadequate maternal $n$-3 fatty acid nutrition to support optimal infant development occurs at maternal intakes of $\leq 80 \mathrm{mg}$ 
DHA/d and milk levels of $<0 \cdot 2 \mathrm{~g}$ DHA/ $100 \mathrm{~g}$ total fatty acids. Data derived from autopsy analysis indicate that the fetus accumulates about $70 \mathrm{mg}$ DHA/d during the last trimester of gestation (Clandinin et al. 1981), and DHA accretion in the human forebrain follows a linear pattern through at least the 12 months after birth (Martinez, 1992). Assuming an average of $37 \mathrm{~g}$ fat $/ \mathrm{l} \mathrm{milk,} \mathrm{a} \mathrm{daily} \mathrm{intake} \mathrm{of}$ $780 \mathrm{ml}$ human milk with $0 \cdot 2 \mathrm{~g}$ DHA $/ 100 \mathrm{~g}$ total fatty acids will provide $56 \mathrm{mg}$ DHA/d to the infant, which is less than projected requirements.

In summary, while the importance of the differences in $n-6$ and $n-3$ fatty acids, particularly differences in DHA between human milk and infant formulas, has been the subject of intense clinical research, the $n-6$ and $n-3$ fatty acids in human milk also vary widely. As a result, there are marked differences in $n-6$ and $n-3$ fatty acid intake among breast-fed infants. Dietary patterns in relation to selection of fats and oils and the choice of whether or not to eat fish appear to be relatively stable. As a result, differences in the $n-6$ and $n-3$ fatty acids in human milk affect not only differences in the supply of $n-6$ and $n-3$ fatty acids to the breast-fed infant, but also differences in the supply of these fatty acids to the infant before birth. The dependence of human milk LA and DHA on the maternal dietary fat composition shows that for infant feeding human milk is not a gold standard for these fatty acids. Dietary guidelines aimed at reducing risk of chronic disease need to be cognisant that when followed by pregnant and lactating women they also have a marked effect on the amount and balance of $n-6$ and $n-3$ fatty acids transferred to the infant before and after birth. The Vancouver studies emphasize the need for dietary fat recommendations for pregnancy and lactation, specific stages of the life cycle involving anabolism and transfer of nutrients to the developing infant. In the absence of dose-response studies to determine safe upper limits for fatty acid supplements during pregnancy, a practical approach, if supplements are to be used, is to use a supplement within the range that would be achieved by currently-recommended intakes of fish $(1 \mathrm{~g}$ fish oil/d).

\section{References}

Bazan NG (2006) Cell survival matters: docosahexaenoic acid signaling, neuroprotection and photoreceptors. Trends in Neurosciences $29,263-271$.

Birch EE, Garfield S, Hoffman DR, Uauy R \& Birch DC (2000) A randomized controlled trial of early dietary supply of longchain polyunsaturated fatty acids and mental development in term infants. Developmental Medicine and Child Neurology 42, 174-181.

Birch EE, Hoffman DR, Uauy R, Birch DG \& Prestidge C (1998) Visual acuity and the essentiality of docosahexaenoic acid and arachidonic acid in the diet of term infants. Pediatric Research 44, 201-209.

Calder PC (2006) Polyunsaturated fatty acids and inflammation. Prostaglandins, Leukotrienes, and Essential Fatty Acids $\mathbf{7 5}$, 197-202.

Calder PC, Krauss-Etschmann S, de Jong EC, Dupont C, Frick JS, Frokiaer H et al. (2006) Early nutrition and immunity: progress and perspectives. British Journal of Nutrition 96, 774-790.
Carlson SE, Ford AJ, Werkman SH, Peeples JM \& Koo WW (1996) Visual acuity and fatty acid status of term infants fed human milk and formulas with and without docosahexaenoate and arachidonate from egg yolk lecithin. Pediatric Research 39, 882-888.

Clandinin MT, Chappell JE, Helm T, Swyer PR \& Chance GW (1981) Fatty acid utilization in perinatal de novo synthesis of tissues. Early Human Development 5, 355-366.

Fewtrell MS (2006) Long-chain polyunsaturated fatty acids in early life: effects on multiple health outcomes. A critical review of current status, gaps and knowledge. Nestlé Nutrition Workshop Series. Paediatric Programme 57, 203-214.

Fidler N, Sauerwald T, Pohl A, Demmelmair H \& Koletzko B (2000) Docosahexaenoic acid transfer into human milk after dietary supplementation a randomized clinical trial. Journal of Lipid Research 41, 1376-1383.

Friesen RW \& Innis SM (2006) Trans fatty acids in human milk in Canada: a decline with the introduction of trans fat food labeling. Journal of Nutrition 136, 1-4.

Gibson RA, Neuman MA \& Makrides M (1997) Effect of increasing breast milk docosahexaenoic acid on plasma and erythrocyte phospholipids fatty acids and neural indices of exclusively breast fed infants. European Journal of Clinical Nutrition 51, 578-584.

Hachey DC, Silber GH, Wong WW \& Garza C (1989) Human lactation. II: Endogenous fatty acid synthesis by the mammary gland. Pediatric Research 25, 63-68.

Heird WC \& Lapillonne A (2005) The role of essential fatty acids in development. Annual Review of Nutrition 25, 549-571.

Helland IB, Saugstad OD, Smith L, Saarem K, Solvoll K, Ganes T \& Drevon CA (2001) Similar effects on infants of n-3 and n-6 fatty acids supplementation to pregnant and lactating women. Pediatrics 108, e82-e91.

Helland IB, Smith L, Saarem K, Saugstad OD \& Drevon CA (2003) Maternal supplementation with very-long-chain $n-3$ fatty acids during pregnancy and lactation augments children's IQ at 4 years of age. Pediatrics 111, e39-e44.

Henderson RA, Jenson RG, Lammi-Keefe CJ, Ferris AM \& Dardick KR (1992) Effect of fish oil on the fatty acid composition of human milk and maternal and infant erythrocytes. Lipids 27, 863-869.

Hoffman DR, Birch EE, Castaneda YS, Fawcett SL, Wheaton DH, Birch DG \& Uauy R (2003) Journal of Pediatrics 142, 669-677.

Innis SM (1991) Essential fatty acids in growth and development. Progress in Lipid Research 30, 39-103.

Innis SM (1992) Human milk and formula fatty acids. Journal of Pediatrics 120, S56-S61.

Innis SM (2003) Perinatal biochemistry and physiology of longchain polyunsaturated fatty acids. Journal of Pediatrics 143, Suppl. 4, S1-S8.

Innis SM (2004) Polyunsaturated fatty acids in human milk: an essential role in infant development. Advances in Experimental Medicine and Biology 554, 27-43.

Innis SM (2006) Trans fatty intakes during pregnancy, infancy and early childhood. Atherosclerosis Supplements 7, 17-20.

Innis SM (2007) Dietary n-3 fatty acids and brain development. Journal of Nutrition (In the Press).

Innis SM, Auestad N \& Siegman JS (1996) Blood lipid docosahexaenoic and arachidonic acid in term gestation infants fed formulas with high docosahexaenoic acid and low eicosapentaenoic acid fish oil. Lipids 31, 617-626.

Innis SM, Dyer R \& Nelson CM (1994) Evidence that palmitic acid is absorbed as $s n-2$ monoacylglycerol from human milk by breast-fed infants. Lipids 29, 541-545.

Innis SM, Gilley J \& Werker J (2001) Are human milk longchain polyunsaturated fatty acids related to visual and neural 
development in breast-fed term infants? Journal of Pediatrics 139, 532-538.

Innis SM \& King DJ (1999) Trans fatty acids in human milk are inversely associated with levels of essential all-cis n-6 and n-3 fatty acids, and determine trans, but not n- 6 and n-3, fatty acids in plasma of breast-fed infants. American Journal of Clinical Nutrition 70, 383-390.

Innis SM, Pinsk V \& Jacobson K (2006) Dietary lipids and intestinal inflammatory disease. Journal of Pediatrics 149, S89-S96.

Insull W, Hirsch J, James J \& Ahrens EH (1959) The fatty acids of human milk II alterations produced by manipulation of calorie balance and exchange of dietary fats. Journal of Clinical Investigation 38, 443-450.

Jensen CL, Maude M, Anderson RE \& Heird WC (2000) Effect of docosahexaenoic acid supplementation of lactating women on the fatty acid composition of breast milk lipids and maternal and infant plasma phospholipids. American Journal of Clinical Nutrition 71, 292S-299S.

Jensen CL, Voigt RG, Prager TC, Zou YL, Fraley JK, Rozelle JC, Turcich MR, Llorente AM, Anderson RE \& Heird WC (2005) Effects of maternal docosahexaenoic acid intake on visual function and neurodevelopment in breastfed term infants. American Journal of Clinical Nutrition 82, 125-132.

Jensen RG (1999) Lipids in human milk. Lipids 34, 1243-1271.

Jensen RG, Ferris AM, Lammi-Keefe CJ \& Henderson RA (1990) Lipids of bovine and human milks: a comparison. Journal of Dairy Science 73, 223-240.

Jorgensen MH, Hernell O, Hughes EL \& Michaelsen KF (2001) Is there a relation between docosahexaenoic acid concentration in mothers' milk and visual development in term infants? Journal of Pediatric Gastroenterology and Nutrition 32, 293296.

Kennedy K, Fewtrell MS, Morely R, Abbott R, Quinlan PT, Wells JC, Bindels JG \& Lucas A (1999) Double-blind, randomized trial of a synthetic triacylglycerol in formula-fed term infants: effects on stool biochemistry, stool characteristics, and bone mineralization. American Journal of Clinical Nutrition 70, 920-927.

Kris-Etherton PM, Taylor DS, Yu-Poh S, Huth P, Moriarty K, Fishell V, Hargrove R, Zhoa G \& Etherton T (2000) Polyunsaturated fatty acids in the food chain in the United States. American Journal of Clinical Nutrition 71, 179S-188S.

Lauritzen L, Hansen HS, Jorgensen MH \& Michaelsen KF (2001) The essentiality of long chain n-3 fatty acids in relation to development and function of the brain and retina. Progress in Lipid Research 40, 1-94.

Lauritzen L, Jorgensen MH, Mikkelsen TB, Skovgaard M, Straarup EM, Olsen SF, Hoy CE \& Michaelsen KF (2004) Maternal fish oil supplementation in lactation: effect on visual acuity and n-3 fatty acid content of infant erythrocytes. Lipids 39, 195-206.
Makrides M, Neumann MA, Simmer K \& Gibson RA (1995) Erythrocyte fatty acids of term infants fed either breast milk, standard formula, or formula supplemented with long-chain polyunsaturates. Lipids 30, 941-948.

Martinez M (1992) Tissue levels of polyunsaturated fatty acids during early human development. Journal of Pediatrics $\mathbf{1 2 0}$, S129-S138.

Neville MC (2001) Anatomy and physiology of lactation. Pediatric Clinics of North America 48, 13-34.

Niu SL, Mitchell DC, Lim SY, Wen ZM, Kim HY, Salmen N Jr \& Litman BJ (2004) Reduced G protein-coupled efficiency in retinal rod outer segments in response to n-3 fatty acid deficiency. Journal of Biological Chemistry 279, 31098-31104.

Ponder DL, Innis SM, Benson JD \& Siegman JS (1992) Docosahexaenoic acid status of term infants fed breast milk or infant formula containing soy oil or corn oil. Pediatric Research 32, 683-688.

Rodriguez-Cruz M, Tovar AR, Palacios-Gonzalez B, del Prado M \& Torres N (2006) Synthesis of long-chain polyunsaturated fatty acids in lactating mammary gland: role of delta 5 and delta 6 desaturases, SREBP-1, PPAR alpha, and PGC-1. Journal of Lipid Research 47, 553-560.

Sanders TAB \& Reddy S (1992) The influence of vegetarian diet on the fatty acid composition of human milk and essential fatty acid status of the infant. Journal of Pediatrics 120, 71S$77 \mathrm{~S}$.

SanGiovanni JP, Berkey CS, Dwyer JT \& Colditz GA (2000) Dietary essential fatty acids, long-chain polyunsaturated fatty acids, and visual resolution acuity in healthy full-term infants: a systematic review. Early Human Development 57, 165-188.

Simopoulos AP (1999) Evolutionary aspects of omega-3 fatty acids in the food supply. Prostaglandins, Leukotrienes, and Essential Fatty Acids 60, 421-429.

Soubias O, Teaque WE \& Gawrish K (2006) Evidence for specificity in lipid-rhodopsin interactions. Journal of Biological Chemistry 281, 33233-33241.

Sprecher H (1999) An update on the pathways of polyunsaturated fatty acid metabolism. Current Opinion in Clinical Nutrition and Metabolic Care 2, 135-138.

Tomarelli RM, Myer BJ, Weaber JR \& Bernhart FW (1968) Effect of positional distribution on the absorption of the fatty acids of human milk and infant formulas. Journal of Nutrition 95, 583-590.

Uauy R \& Dangour AD (2006) Nutrition in brain development and aging role of essential fatty acids. Nutrition Reviews $\mathbf{6 4}$, S24-S33.

Williams CM \& Burdge G (2006) Long-chain n-3PUFA plant $\mathrm{v}$ marine sources. Proceedings of the Nutrition Society $\mathbf{6 5}$, $42-50$.

Yukas R, Pramul K \& Lien EL (2006) Human milk fatty acid composition from nine countries varies most in DHA. Lipids 42, 851-858. 